\title{
Care of the Elderly Symposium
}

\author{
E Dearden \\ StR in Geriatric Medicine, South East Scotland Deanery, South East Scotland, UK
}

The Care of the Elderly Symposium was held I 2 April 2013 at the Royal College of Physicians of Edinburgh

DECLARATIONS OF INTERESTS No conflicts of interest declared.

\author{
Correspondence to E Dearden \\ Centre for Medical Education \\ College of Medicine \\ $\&$ Veterinary Medicine \\ The Chancellor's Building \\ 49 Little France Crescent \\ Edinburgh EHI6 4SB, UK \\ tel. $+44(0) 13 I 24264 I 2$ \\ e-mail effie.dearden@nhs.net
}

\section{INTRODUCTION}

With an ageing population and a challenging economic climate, the need for an effective approach to healthcare for the elderly has never been greater. This symposium addressed the difficulties of establishing the aspects of care to be measured and the tools that are available, focusing on an area at the forefront of recent debate: quality.

\section{WHAT THE PHYSICIAN NEEDS TO MEASURE IN PRACTICE}

A total of $46 \%$ of attendees had not used urine frequency volume charts despite these being an effective and non-invasive method of assessing continence. Dr Ann Capewell (Consultant Physician in Medicine for Older People, St Helens and Knowsley Teaching Hospitals) presented a practical approach to assessing continence, focusing on frequency/volume charting and bladder scanning alongside patient-reported quality of life outcomes rather than focusing on urodynamic testing, which is not proven to improve outcomes in a geriatric population.

Over half of all dementia sufferers $(60 \%)$ remain undiagnosed. Dr Duncan Forsyth (Consultant Geriatrician, Addenbrooke's Hospital) showed the difficulties of measuring cognition. Comprehension, attitude, strategies and interests tests (CASI) cover all six domains of cognition (attention/working memory, new verbal learning and recall, expressive language, visual construction, executive function and abstract reasoning), but they are time-consuming to perform and therefore opportunities to do so at the hospital front door or GP surgery are limited.' Simple questions however are very effective:'has this person been more forgetful over the last year such that it significantly interferes with daily life?'
Half of all community-dwelling older adults and $80 \%$ of those in nursing homes suffer pain (commonly arthritis, back pain or angina). It is difficult, however, to assess this pain among those with cognitive impairment. Dr Sinead O'Mahony (Clinical Senior Lecturer, University Hospital LLandough) showed that the use of numeric and verbal descriptor intensity scales is validated in those with mild to moderate cognitive impairment. Observation (with or without aids like the Abbey pain scale) by familiar carers also improves the detection of pain in those with

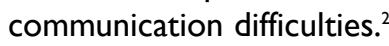

\section{MEASURING 'SUCCESS' IN HOW WE CARE}

Reducing avoidable hospital admissions should improve the quality and efficiency of care. Dr Sarah Purdy (Reader in Primary Healthcare, University of Bristol) examined the difficulties of establishing which are avoidable. Some risk factors are not easy to modify (deprivation and low social capital), others suggest modifiable aspects (proximity to emergency departments predicts higher admission rates for example) and risk factors often interact. Continuity of GP care, prompt senior decision-making at the front door, structured discharge planning and better end-of-life care planning are effective. ${ }^{3}$

The Sydney Watson Smith endowed lecture was delivered by Lord Sutherland of Houndwood. Using the analogy of Oscar Wilde's Dorian Grey, he outlined the urgent need for a response to the ageing picture in the attic that has been ignored for too long - no longer able to be pushed out of sight and out of mind. The ageing demographic brings with it more of the chronic diseases associated with older age and rising care costs to match, challenging both health and social care. Integration of the two systems should allow for more holistic care and a single point of commissioning, assessing and accountability and a single budget; however, there is no guarantee that this alone will reduce costs. 


\section{LIVING WELL IN LATER LIFE - CAN WE MEASURE IT?}

Professor Roger Watson (Professor of Nursing, University of Hull) offered an approach to developing activities of daily living (ADL) scales. Scales must be easy to use, but we should also look for a score that is a precise statement of function and prediction of future difficulties based on the patient's current status. The Townsend functional ability scale (which covers nine ADLs from heavy housework to cutting your own toenails and rates how easily they can be completed or not) demonstrates these elements and is validated in community-dwelling older adults. ${ }^{4}$

Professor Matteo Cesari (Institute of Aging, University of Toulouse) showed how the frailty phenotype can inform a screening tool in community-dwelling older adults. People who are identified as potentially frail were referred for multi-disciplinary assessment and a high incidence of undiagnosed co-morbidity was found, including cognitive impairment in two-thirds.

\section{MEASURING THE UNMEASURABLE}

Happiness is culturally and societally dependent. Dr Jan Eichhorn (Sociologist, Applied Quantitative Methods Network, University of Edinburgh) described how its subjectivity can be harnessed and measured. Hedonic affect (the 'theoretical summation of infinite separate momentary pleasures and pains') or subjective happiness ('life as a whole', encompassing past, present and future) are used. Individual happiness is surprisingly stable; people adapt to changing circumstances. ${ }^{5}$

\section{REFERENCES}

I Cullen B, O'Neill B, Evans JJ et al. A review of screening tests for cognitive impairment.J Neurol Neurosurg Psychiatry 2007; 78:790-9. http://dx.doi.org//0.1 I36/jnnp.2006.0954|4

2 Zwakhalen SM, Hamers JP, Abu-Saad HH et al. Pain in elderly people with severe dementia: a systematic review of behavioural pain assessment tools. BMC Geriatrics 2006; 6:3. http://dx.doi. org/l0.1 I86//47|-23/8-6-3

3 Purdy S. Avoiding hospital admissions. What does the research evidence say [Internet]? London:The King's Fund; 2010 [cited 2013 June 14] Available from: http://www.kingsfund.org.uk/publications/avoiding hospital.html
A total of $33 \%$ of people between the ages of 75 and 85 remain sexually active. Professor Margot Gosney (Director of Clinical Health Sciences, University of Reading) showed that interest in sex declines with age, but by less than we think. Basic assessment, involving a simple history, asking whether function is intact, the frequency and quality of erections and orgasms, should be routine. Patients are often reluctant to raise concerns. The onus is therefore on us to address this important aspect of their lives.

Professor Paul Kind (Professor of Health Outcome Measurement, University of Leeds) discussed the difficulties of measuring quality of life; it is also essential to align what we measure to the priorities of patients. The EQ-5D health questionnaire can be used as a measure of quality of life and comprises five dimensions: mobility, self-care, usual activities, pain/discomfort and anxiety/depression. The results are recorded in a visual analogue scale. The results can be used as a quantitative measure, which has wide-ranging uses including providing feedback on progress to clinicians, patients and families, assessing service performance and establishing health policy.

\section{TAKE HOME MESSAGE}

This symposium emphasised the range of tools available to measure outcomes and progress in care of the elderly. The most interesting and challenging ones are those which take a holistic view; they are easy to measure, involve simple questions and can be implemented by us all.

4 Fieo R, Watson R, Deary IJ et al. A revised activities of daily living/ instrumental activities of daily living instrument increase interpretive power: theoretical application for functional tasks exercise. Gerontology 2010; 56:483-90. http://dx.doi.org/I0.I I59/00027/603

5 Diener E, Lucas R. Personality and subjective well-being. In: Kahneman D, Diener E, Schwarz N, editors. Well-being:the foundations of hedonic psychology. New York: Russell Sage Foundation; 1999. 